\title{
Research Article \\ Coordination Game Analysis through Penalty Scheme in Freight Intermodal Service
}

\author{
Jian Liu, Jianning Yu, and Yinzhen Li \\ School of Traffic and Transportation, Lanzhou Jiaotong University, Lanzhou 730070, China \\ Correspondence should be addressed to Jian Liu, liujianlz@sohu.com
}

Received 10 May 2012; Revised 14 August 2012; Accepted 15 August 2012

Academic Editor: Wuhong Wang

Copyright $@ 2012$ Jian Liu et al. This is an open access article distributed under the Creative Commons Attribution License, which permits unrestricted use, distribution, and reproduction in any medium, provided the original work is properly cited.

\begin{abstract}
We study coordination mechanisms through penalty schemes to cooperate the behavior of two firms as successive segment carriers to make transport plan separate in freight intermodal market. Based on the different cost structure and service level constraint to two firms, we compare the decision making in two possible decision systems, that is, centralized system and decentralized system. In a centralized system - the first best case as a benchmark is contrasted with decentralized system. In the decentralized system, a Stackelberg game model is formulated between two firms. Some discordant decisions would be made by firm I's overestimate motivation and firm II's undersupply motivation. Our primary objective is to design penalty schemes to coordinate the interactions for two firms. The study shows in a decentralized system, setting suitable penalty schemes can coordinate the two firms' decision. We also study the feasible range of penalty parameters, and some important managerial insights are then deduced. In the end, a numerical example is provided to verify the validity of results, some concluding remarks are presented subsequently.
\end{abstract}

\section{Introduction}

Over the past decades, the increasing importance of international logistics has forced many firms to consider utilizing intermodalism to substantially decrease logistics costs. Intermodal freight transportation can be defined as the movement of goods from origins to destinations in one and the same loading unit or vehicle by successive transportation modes. Its goal is to provide an integration and effective seamless door-to-door service. During the whole operation process, there are always more than two separate firms involved in one intermodal freight transport service, therefore, the multiside participation is an outstanding feature, and the coordination or cooperation among the multiactor's is a core problem, which has been considered as a challenging issue by many practitioners and researchers. 
Numerous studies have been done on the intermodal freight transportation industry. Macharis and Bontekoning [1] and Bontekoning et al. [2] provided an insightful review of the development and the related study in the intermodal freight transport. They argued that intermodal freight transportation research is emerging as a new transportation research application field, and it still is in a preparadigmatic phase. Specifically, because the physical network can be easily modeled as a network flow problem and there are especially efficient network flow algorithms, many researches use network to simulate actual intermodal operations [3-7]. However, most papers above focus on the operation management by single decision maker with the objective of expected profit maximization or expected cost minimization, and little account of interactions based on the multiactor's behavior is taken. Game theory is an appropriate tool for analyzing real situations where multiple agents are involved in decision and their actions are interrelated. Hurtely and Petersen [8] established a game-theoretic model to analyze the equilibrium behavior between carrier and shipper in freight transport market, by using a particular form of nonlinear tariff, they showed that the user equilibrium and system optimum can be simultaneously satisfied in an incomplete market. Xiao and Yang [9] subsequently developed a partially noncooperative game model among shippers, carriers, and infrastructure companies. Zhang et al. [10] examined the effect of multimodal integration between two different transport chains, they found an improvement in multimodal integration by a forwarder airline alliance, and it would not increase the alliance's output but improve both consumer surplus and total surplus.

Nowadays, with the change of production mode from centralized system to decentralized system, a new organization mode—virtual organization (VO)—is rising. The cooperation and coordination have become an important management issue with which more and more decentralized decision cases appeared in real business practice. It is a great challenge to traditional administration and management. There were extensive literatures which focus on the coordination among multiactors especially on supply chain management. Since the outcome in decentralized system is inefficient, cooperation among firms by means of coordination of actions may improve the individual profits. Nagarajan and Sosic [11] and Guardiola et al. [12] studied the cooperation in supply chain by cooperative game theory. Celikbas et al. [13] studied coordination mechanisms through penalty schemes between manufacturing and marketing departments which enable organizations to match demand forecasts with production quantities. Raju and Roy [14] studied a game model to understand how firm and industry characteristics moderate the effect of market information on cooperation. Cachon [15] reviewed the supply chain coordination with contracts, he discussed numerous supply chain models, and in each model the supply chain's actions are identified. Nevertheless, most studies on the coordination problem in a decentralized system are set in manufacturing industry and focus on how to coordinate interactions among supplier, manufacturer, and retailer in supply chains, seldom involve freight transport market, especially on how to coordinate participants' behavior (shipper, carrier, forwarder, etc.) in intermodal operation process. In above studies, the transport is not considered as an independent system but incorporated in the process of supply, manufacture, or retail.

In fact, based on the increase of global business, a kind of new organization structure, that is, VO with temporary, dynamic, and loose characteristics is being established in intermodal business process. It does require developing proper mechanisms to coordinate the behavior of all separate actors. In this paper, we develop incentive mechanisms for coordination actions to make transport plan between the two separate firms which offer complementary transportation service in an intermodal freight transport market. By comparing the performance of centralized and decentralized system under a stochastic 


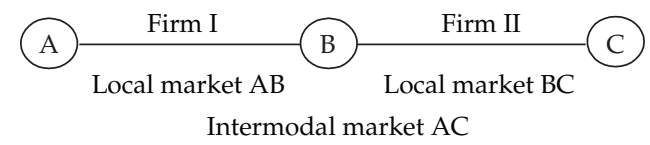

Figure 1: An intermodal market network.

demand, some theoretical analyses on game theory are deduced and some managerial insights are proposed subsequently.

The rest of the paper is organized as follows. Section 2 describes business background and sets up our basic model. Section 3 sets suitable penalty scheme to coordinate between the two separate firms. In Section 4, a case study is used to testify the propositions and results. In the end, some concluding remarks are presented in Section 5.

\section{Model}

\subsection{Scenario and Notation}

In order to describe the interactions among the different agents, we consider a simple intermodal network, as depicted in Figure 1, the network consists of three nodes, namely, A, $\mathrm{B}$, and $\mathrm{C}$. Consequently, there are three origin-destination markets, namely, $\mathrm{AB}, \mathrm{BC}$, and $\mathrm{AC}$, of which $\mathrm{AB}$ involves ground transportation of cargo between $\mathrm{A}$ and $\mathrm{B}$ by truck, whereas $\mathrm{BC}$ involves transportation between $B$ and $C$ by train. While $A C$ involves two different transport modes and may be referred to as a potential intermodal market. We assume there are two separate firms, firm $I$ and firm $I I$, that either control the transport infrastructure or provide complementary freight transportation service in $\mathrm{AB}$ and $\mathrm{BC}$ transport market separately. After market research, the two firms wish cooperatively in AC market to develop a long haul intermodal freight service, in which firm $I$ is the first segment carrier and firm $I I$ is the second segment carrier. The two firms would make transport plan before providing the intermodal service. We discuss the two decision systems, that is, decentralized and centralized systems. In a centralized system - the first best case as a benchmark which contrasts with decentralized system, the two firms decide together on the quantities to distribute transport capacity by optimizing the total expected profits. In a decentralized system, firm I and firm II distribute transport capacity separately by maximizing their individual profit. That is a Stackelberg game actually. Firm I, firstly, as the first segment carrier, forecasts, demands, and decides the transport capacity. Firm II makes corresponding transport capacity decision based on the above decision. Because of different cost structure and opportunistic behavior of two firms, some discordant decisions would be made subsequently. In the game, firm $I$ has overestimate motivation based on the restriction of service level and total cost, and then, by considering the opportunity cost, firm II always distributes less transport capacity in order to prevent capacity waste. (In China, e.g., the railway transport capacity is always in short supply. After considering factors such as types of car, stations, directions, among others, which is opportunity cost actually, the railway company often distributes less transport capacity than demand.) Their decisions are coupled. In order to solve the problem, a penalty scheme is designed to coordinate behaviors of two firms, that is, an overestimate penalty is charged to firm $I$, and an undersupply penalty is charged to firm II. The penalty scheme would be set up by the third party with authority. 
To capture uncertainty in market demand, we assume the demand is a random variable, and the demand distribution is assumed to be known to both two firms. The timing of events is as follows. First, the third party with authority sets the overestimate penalties to firm $I$ and the undersupply penalties to firm II. Second, a Stackelberg game is played between two firms. Firm $I$ is the Stackelberg leader and making decision of distributing transport capacity and then reveal it to firm II. The firm II, the follower, determines its own capacity assignment plan based on this message. The final determinate intermodal transport capacity realization follows the minimum quantities of two firms' capacity assignment plan and the firms will be penalized if necessary.

The notation used in this paper is as follows: $D$-demand, assumed to be an absolutely continuous random variable; $f(x), F(x)$-density function and cumulative distribution function of $D$, and $f(x)>0 ; F^{-1}(x)$-inverse function of $F(x) ; P_{I I}^{u}$-under-supply penalty of transport capacity per item for firm II; $P_{I}^{o}$-over-estimate penalty per item for firm $I$; $p_{i}$-transport price per item for firm $i, i=I, I I ; c_{i}$-variable cost for firm $i, i=I, I I ; c_{I I}^{w}$ opportunity cost per over-supply item for firm II; $q_{i}$-optimal transport capacity by firm $i$ in the decentralized system, $i=I, I I ; q_{c}$-joint optimal capacity in the centralized system; $\alpha$-given service level objective, $0 \leq \alpha \leq 1 ; I(\cdot)-0-1$ indicator function, when $(\cdot)$ is satisfied, then $I(\cdot)=1$, otherwise $I(\cdot)=0 ; E(\cdot)$ —expectation operator.

In this paper, we adopt the common assumption that all parameters of demand functions are common knowledge to both firms, and $p_{i}>c_{i}(i=I, I I)$ is always satisfied.

\subsection{Basic Model}

In a decentralized system, the two separate firms distribute optimal transport capacity sequentially based on the objective of maximizing individual profit. We assume two firms with different cost structure. Firm $I$, as the first segment intermodal service provider, the variable cost is taken into consideration, and a given service level must be satisfied at the same time. For firm II, as the second carrier, except the variable cost, the waste cost from oversupply should be considered, which is an opportunity cost virtually. If not penalized, firm I will give an overestimate transport capacity to firm II, and firm II will assign less capacity than the given overestimate transport capacity. The final realized intermodal shipping volume which is decided on the minimum value among two firms' decision on transport capacity and the

demand is correspondingly reduced. Therefore, a proper penalty scheme for two firms is designed necessarily. Firm I's objective is given as follows:

$$
\begin{aligned}
& \max R_{I}\left(q_{I}\right)=\left(p_{I}-c_{I}\right) \min \left\{q_{I}, q_{I I}\left(q_{I}\right), D\right\}-P_{I}^{o}\left[q_{I}-D\right]^{+} I\left(D \leq q_{I I}\right) \\
& \text { s.t. } \operatorname{pr}\left\{q_{I} \geq D\right\} \geq \alpha .
\end{aligned}
$$

$R_{I}\left(q_{I}\right)$ is the profit function to firm $I$. The profit function consists of two parts. The first part is the revenue for providing intermodal service, where $\min \left\{q_{I}, q_{I I}, D\right\}$ is the final realized intermodal shipping volume, and $q_{I I}$ is the transport capacity amount decided by firm $I I$ in response to firm I's decision $q_{I}$. The second part is the penalty for overestimate, that means if the firm II's decision $q_{I I}$ which is caused by firm I's overestimate decision is greater than the realized demand $D$, then an overestimate penalty to firm $I$ is given by $p_{I}^{o}\left[q_{I}-D\right]^{+} I\left(D \leq q_{I I}\right)$, where $I\left(D \leq q_{I I}\right)$ is a $0-1$ indicator function and $\left[q_{I}-D\right]^{+}=\max \left\{q_{I}-D, 0\right\}$. Here, the firm $I$ is penalized to the amounts $\left[q_{I}-D\right]^{+}$only when the condition $I\left(D \leq q_{I I}\right)=1$ is satisfied. 
That implies if the firm II's capacity is always in short supply (less than the realized demand $\left.q_{I I}<D\right)$, then the firm $I$ should not be penalized for even an overestimate decision. The constraint means the probability that the transport demand should be satisfied is not less than the given service level $\alpha$.

The firm II's decision is to maximize the profit function itself:

$$
\max R_{I I}\left(q_{I I}\right)=\left(p_{I I}-c_{I I}\right) \min \left\{q_{I}, q_{I I}, D\right\}-c_{I I}^{w}\left[q_{I I}-\min \left\{D, q_{I}\right\}\right]^{+}-P_{I I}^{u}\left[\min \left\{q_{I}, D\right\}-q_{I I}\right]^{+}
$$

The profit function consists of three parts. The first part is the revenue for providing intermodal service. The second part is the cost of waste transport capacity for making the oversupply transport plan, where $\left[q_{I I}-\min \left\{D, q_{I}\right\}\right]^{+}$are wastage. That implies if firm II distributes greater amount of transport capacity than the $q_{I}$ or demand $D$, the waste cost would rise. It is the substantial opportunity cost. The third part is the penalty for the undersupply decision. If the decision $q_{I I}$ is less than the $q_{I}$ or demand $D$, then $q_{I I}$ will be a bottleneck to the intermodal operation. Firm II, therefore, have to improve their decisions under the pressure of the penalty for undersupply.

Using backward induction algorithm to analyze the Stackelberg game. First, from problem (2.2), the following expect profit functions of $R_{I I}$ are derived. When $q_{I I} \leq q_{I}$ is satisfied, we have

$$
\begin{aligned}
E\left(R_{I I}\left(q_{I I}\right)\right)= & \left(p_{I I}-c_{I I}\right)\left[q_{I I} \int_{q_{I I}}^{\infty} f(x) d x+\int_{0}^{q_{I I}} x f(x) d x\right]-c_{I I}^{w} \int_{0}^{q_{I I}}\left(q_{I I}-x\right) f(x) d x \\
& -P_{I I}^{u}\left[\int_{q_{I}}^{\infty}\left(q_{I}-q_{I I}\right) F(x) d x+\int_{q_{I I}}^{q_{I}}\left(x-q_{I I}\right) F(x) d x\right] \\
= & \left(p_{I I}-c_{I I}\right)\left[q_{I I}-\int_{0}^{q_{I I}} F(x) d x\right]-c_{I I}^{w} \int_{0}^{q_{I I}} F(x) d x-P_{I I}^{u}\left[q_{I}-q_{I I}-\int_{q_{I I}}^{q_{I}} F(x) d x\right] .
\end{aligned}
$$

When $q_{I I} \geq q_{I}$ is satisfied, the expect profit function is

$$
\begin{aligned}
E\left(R_{I I}\left(q_{I I}\right)\right)= & \left(p_{I I}-c_{I I}\right)\left[\int_{q_{I}}^{\infty} q_{I} f(x) d x+\int_{0}^{q_{I}} x f(x) d x\right] \\
& -c_{I I}^{w}\left[\int_{q_{I}}^{\infty}\left(q_{I I}-q_{I}\right) f(x) d x+\int_{0}^{q_{I}}\left(q_{I I}-x\right) f(x) d x\right] \\
= & \left(p_{I I}-c_{I I}\right)\left[q_{I}-\int_{0}^{q_{I}} F(x) d x\right]-c_{I I}^{w}\left[q_{I I}-q_{I}+\int_{0}^{q_{I}} F(x) d x\right] .
\end{aligned}
$$

Based on the $f(x)>0, p_{i}>c_{i}$, and $\partial^{2} E\left(R_{I I}\right) / \partial q_{I I}^{2} \leq 0$, it is easy to know $R_{I I}\left(q_{I I}\right)$ is concave in $q_{I I}$ and the global optimal solution is existed. 
When $q_{I I} \geq q_{I}$, we have $\partial E\left(R_{I I}\left(q_{I I}\right)\right) / \partial q_{I I}=-c_{b}^{w}<0$. Therefore, $q_{I I}$ that maximizes $R_{I I}$ should satisfy $q_{I I} \leq q_{I}$. For $q_{I I} \leq q_{I}$, from the first-order condition,

$$
\begin{aligned}
& \frac{\partial E\left(R_{I I}\left(q_{I I}\right)\right)}{\partial q_{I I}}=\left(p_{I I}-c_{I I}\right)\left[1-F\left(q_{I I}\right)\right]-c_{I I}^{w} F\left(q_{I I}\right)+P_{I I}^{u}\left[1-F\left(q_{I I}\right)\right]=0 \\
& \Longrightarrow F\left(q_{I I}^{*}\right)=1-\frac{c_{I I}^{w}}{p_{I I}-c_{I I}+P_{I I}^{u}+c_{I I}^{w}} \Longrightarrow q_{I I}^{*}=F^{-1}\left(1-\frac{c_{I I}^{w}}{p_{I I}-c_{I I}+P_{I I}^{u}+c_{I I}^{w}}\right)
\end{aligned}
$$

If $q_{I I}^{*} \leq q_{I}$, then $q_{I I}=q_{I I}^{*}$ to maximize $R_{I I}$, otherwise, $q_{I I}=q_{I}$ to maximize $R_{I I}$. Therefore, the reaction function of $q_{I I}$ is given by

$$
q_{I I}\left(q_{I}\right)=\min \left\{F^{-1}\left(1-\frac{c_{I I}^{w}}{p_{I I}-c_{I I}+P_{I I}^{u}+c_{I I}^{w}}\right), q_{I}\right\}
$$

From (2.6), we have $q_{I I} \leq q_{I}$ that implies it is never optimal to firm II to assign more transport capacity than firm I's decision. The $q_{I}$ is always considered as upper boundary while the firm II makes decision to $q_{I I}$, and with the increase of punishment $P_{I I}^{u}, q_{I I}$ will increase subsequently.

Firm I's decision is affected by the service level $\alpha$. Here, we define that the service level $\alpha$ is the given probability to meet the intermodal demand. Based on the reaction function (2.6), the Firm I's decision, that is, problem (2.1) can be described as the solution of the following programming problem:

$$
\begin{aligned}
& \max R_{I}\left(q_{I}\right)=R_{I}\left(q_{I}\right)=\left(p_{I}-c_{I}\right) \min \left\{q_{I}, q_{I I}, D\right\}-P_{I}^{o}\left[q_{I}-D\right]^{+} I\left(D \leq q_{I I}\right) \\
& \text { s.t. }\left\{\begin{array}{l}
q_{I I}=\min \left\{q_{I}, F^{-1}\left(1-\frac{c_{I I}^{w}}{p_{I I}-c_{I I}+P_{I I}^{u}+c_{I I}^{w}}\right)\right\}, \\
q_{I} \geq F^{-1}(\alpha),
\end{array}\right.
\end{aligned}
$$

where the constraint condition $q_{I} \geq F^{-1}(\alpha)$ is from this transformation: $\operatorname{pr}\left\{q_{I} \geq D\right\} \geq \alpha \Rightarrow$ $q_{I} \geq F^{-1}(\alpha)$.

From the reaction function (2.6), when $q_{I} \geq F^{-1}\left(1-c_{I I}^{w} /\left(p_{I I}-c_{I I}+P_{I I}^{u}+c_{I I}^{w}\right)\right)$ is satisfied, we have $q_{I I}=F^{-1}\left(1-c_{I I}^{w} /\left(p_{I I}-c_{I I}+P_{I I}^{u}+c_{I I}^{w}\right)\right)$, and the expect profit function is

$$
\begin{aligned}
E\left(R_{I}\left(q_{I}\right)\right) & =\left(p_{I}-c_{I}\right)\left[q_{I I} \int_{q_{I I}}^{\infty} f(x) d x-\int_{0}^{q_{I I}} x f(x) d x\right]-P_{I}^{o} \int_{0}^{q_{I I}}\left(q_{I}-x\right) f(x) d x \\
& =\left(p_{I}-c_{I}\right)\left[q_{I I}-\int_{0}^{q_{I I}} F(x)\right]-P_{I}^{o}\left[\left(q_{1}-q_{I I}\right) F\left(q_{I I}\right)+\int_{0}^{q_{I I}} F(x) d x\right] .
\end{aligned}
$$


When $q_{I} \leq F^{-1}\left(1-c_{I I}^{w} /\left(p_{I I}-c_{I I}+P_{I I}^{u}+c_{I I}^{w}\right)\right)$ is satisfied, we have $q_{I}=q_{I I}$, and the expect profit function is

$$
\begin{aligned}
E\left(R_{I}\left(q_{I}\right)\right) & =\left(p_{I}-c_{I}\right)\left[q_{I} \int_{q_{I}}^{\infty} f(x) d x-\int_{0}^{q_{I}} x f(x) d x\right]-P_{I}^{o} \int_{0}^{q_{I}}\left(q_{I}-x\right) f(x) d x \\
& =\left(p_{I}-c_{I}\right)\left[q_{I}-\int_{0}^{q_{I}} F(x) d x\right]-P_{I}^{o} \int_{0}^{q_{I}} F(x) d x .
\end{aligned}
$$

It is easy to prove that $R_{I}\left(q_{I}\right)$ is concave in $q_{I}$, and the global optimal solution is existed by the function (2.8) and (2.9). The constraint in problem (2.7) implies that if $\alpha \geq 1-c_{I I}^{w} /\left(p_{I I}-\right.$ $\left.c_{I I}+P_{I I}^{u}+c_{I I}^{w}\right)$ is satisfied, then the constraint conditions are converted into only one item, that is, $q_{I} \geq F^{-1}(\alpha)$. If $\alpha \leq 1-c_{I I}^{w} /\left(p_{I I}-c_{I I}+P_{I I}^{u}+c_{I I}^{w}\right)$ is satisfied, then the constraint in problem (2.7) is converted into two items, that is, $q_{I} \geq F^{-1}\left(1-c_{I I}^{w} /\left(p_{I I}-c_{I I}+P_{I I}^{u}+c_{I I}^{w}\right)\right)$ (and then $\left.q_{I I}=F^{-1}\left(1-c_{I I}^{w} /\left(p_{I I}-c_{I I}+P_{I I}^{u}+c_{I I}^{w}\right)\right)\right)$ or $F^{-1}(\alpha) \leq q_{I} \leq F^{-1}\left(1-c_{I I}^{w} /\left(p_{I I}-c_{I I}+P_{I I}^{u}+c_{I I}^{w}\right)\right)$, and then $q_{I}=q_{I I}$. After solving the problem (2.7), we summarize the following Proposition.

Proposition 2.1. In a Stackelberg game on making intermodal transport capacity plan, firm I is penalized for overestimate by $p_{I}^{o}$ and firm II for undersupply by $p_{I I}^{u}$, and the subgame perfect Nash equilibrium is follows:

(i) if the objective service level satisfies the condition $\alpha>1-c_{I I}^{w} /\left(p_{I I}-c_{I I}+P_{I I}^{u}+c_{I I}^{w}\right)$, then $q_{I}=F^{-1}(\alpha)$ and $q_{I I}=F^{-1}\left(1-\left(c_{I I}^{w} /\left(p_{I I}-c_{I I}+P_{I I}^{u}+c_{I I}^{w}\right)\right)\right) ;$

(ii) if the objective service level satisfies the condition $\left.\alpha \leq 1-c_{I I}^{w} /\left(p_{I I}-c_{I I}+P_{I I}^{u}+c_{I I}^{w}\right)\right)$, then $q_{I}=q_{I I}$ and

$$
q_{I}=\left\{\begin{array}{c}
F^{-1}\left(\frac{p_{I}-c_{I}}{p_{I}-c_{I}+P_{I}^{o}}\right), \text { if } F^{-1}(\alpha) \leq F^{-1}\left(\frac{p_{I}-c_{I}}{p_{I}-c_{I}+P_{I}^{o}}\right) \leq F^{-1} \mathcal{A} \\
F^{-1} \mathcal{A}, \text { if } F^{-1}(\alpha) \leq F^{-1} \mathcal{A}<F^{-1}\left(\frac{p_{I}-c_{I}}{p_{I}-c_{I}+P_{I}^{o}}\right) \\
F^{-1}(\alpha), \text { if } F^{-1}\left(\frac{p_{I}-c_{I}}{p_{I}-c_{I}+P_{I}^{o}}\right)<F^{-1}(\alpha) \leq F^{-1} A
\end{array}\right\},
$$

where $A$ denotes $\left(1-\left(c_{I I}^{w} /\left(p_{I I}-c_{I I}+P_{I I}^{u}+c_{I I}^{w}\right)\right)\right)$.

Note that, from the equilibrium transport capacity expression in Proposition 2.1, we know when a higher service level is given $\left(\alpha>1-c_{I I}^{w} /\left(p_{I I}-c_{I I}+P_{I I}^{u}+c_{I I}^{w}\right)\right)$, we always have $q_{I}>q_{I I}$. Meanwhile, the firm I's decision is determined by the given service level, and the penalties mainly restrict undersupply to firm II. When a lower service level is given $\left(\alpha \leq 1-c_{I I}^{w} /\left(p_{I I}-c_{I I}+P_{I I}^{u}+c_{I I}^{w}\right)\right)$, we always have $q_{I}=q_{I I}$. The penalties do not only restrict overestimate to firm $I$ but restrict undersupply to firm II.

\section{Penalty Scheme}

In this section, we first analyze the centralized system-the first best case as a benchmark, wherein two firms maximize their joint profit. In a centralized system, firm $I$ is still the first 
segment carrier and firm II is the second segment carrier, and they join together to determine the amount $q_{c}$ of intermodal transport plan with the objective of maximizing their combined profits. The objective for maximizing joint profit is given as

$$
\begin{aligned}
& \max R_{c}=\left(p_{I}+p_{I I}-c_{I}-c_{I I}\right) \min \left\{q_{c}, D\right\}-c_{I I}^{w}\left[q_{c}-\min \left\{q_{c}, D\right\}\right]^{+} \\
& \text {s.t. } \operatorname{pr}\left\{D \leq q_{c}\right\} \geq \alpha,
\end{aligned}
$$

where $\min \left\{q_{c}, D\right\}$ is the final realized intermodal shipping volume, $\left[q_{c}-\min \left\{q_{c}, D\right\}\right]^{+}$is the waste capacity for overestimate. In order to draw comparison with the decentralized system easily, the transport revenue, variable cost, and opportunity cost on overestimate are included in the joint profit objective.

From (3.1), we know the expect profit function of $R_{c}$ is

$$
E\left(R_{c}\right)=\left(p_{I}+p_{I I}-c_{I}-c_{I I}\right)\left[q_{c}-\int_{0}^{q_{c}} F(x) d x\right]-c_{I I}^{w} \int_{0}^{q_{c}} F(x) d x
$$

The constraint condition is converted to $q_{c} \geq F^{-1}(\alpha)$, so the optimal solution of function (3.1) is

$$
q_{c}=\max \left\{F^{-1}\left(1-\frac{c_{I I}^{w}}{p_{I}+p_{I I}-c_{I}-c_{I I}+c_{I I}^{w}}\right), F^{-1}(\alpha)\right\} .
$$

Proposition 3.1. In a centralized system, with the constraint of service level $\alpha$, the joint transport capacity optimal decision is $q_{c}=\max \left\{F^{-1}\left(1-\left(c_{I I}^{w} /\left(p_{I}+p_{I I}-c_{I}-c_{I I}+c_{I I}^{w}\right)\right)\right), F^{-1}(\alpha)\right\}$.

Proposition 3.1 shows that given $\alpha^{*}=1-c_{I I}^{w} /\left(p_{I}+p_{I I}-c_{I}-c_{I I}+c_{I I}^{w}\right)$ is a critical point. When $\alpha<\alpha^{*}$ is satisfied, that is, setting a lesser objective service level, the programming (3.1) is a no constraint problem actually, and the final transport capacity is $q_{c}=F^{-1}\left(1-c_{I I}^{w} /\left(p_{I}+\right.\right.$ $\left.\left.p_{I I}-c_{I}-c_{I I}+c_{I I}^{w}\right)\right)$ which is the optimal solution to maximize the joint profit, but it is not optimal to shipper. Meanwhile, the carrier has greater welfare. When $\alpha>\alpha^{*}$ is held, the final transport capacity is $q_{c}=F^{-1}(\alpha)$. Though the whole transport capacity $q_{c}$ increases, however, it is not optimal to maximize the joint profit. Meanwhile, the shipper has greater welfare for more consumer surplus.

Next, we develop penalty schemes so that the decentralized system performs as well as the centralized system. Based on the Proposition 3.1, we consider two cases with different constraint of service level. For the convenience to the analysis subsequently, the following notations are introduced:

$$
\begin{gathered}
F_{1}=F^{-1}\left(1-\frac{c_{I I}^{w}}{p_{I I}-c_{I I}+P_{I I}^{u}+c_{I I}^{w}}\right), \quad F_{2}=F^{-1}\left(\frac{p_{I}-c_{I}}{p_{I}-c_{I}+P_{I}^{o}}\right), \\
F_{3}=F^{-1}\left(1-\frac{c_{I I}^{w}}{p_{I}+p_{I I}-c_{I}-c_{I I}+c_{I I}^{w}}\right) .
\end{gathered}
$$


Case 1. If $\alpha \leq \alpha^{*}$, then the mathematical programming (3.1) is an unconstraint problem, and the optimal solution $q_{c}=F_{3}$. Let

$$
\begin{aligned}
& F_{1}=F_{3}, \quad F_{2}=F_{3} \\
& \Longrightarrow P_{I I}^{u}=p_{I}-c_{I}=\Delta_{1}, \quad P_{I}^{o}=\frac{\left(p_{I}-c_{I}\right) c_{I I}^{w}}{p_{I}+p_{I I}-c_{I}-c_{I I}}=\Delta_{2} .
\end{aligned}
$$

From Proposition 3.1, we have $q_{I}=q_{I I}=q_{c}=F_{3}$, the transport capacity decisions in both decentralized system and centralized system are identical and the penalty scheme coordinates the two firms' behaviors. After further discussion, Proposition 3.2 is summarized subsequently.

Proposition 3.2. When the condition $\alpha \leq \alpha^{*}$ is satisfied, if (i) $P_{I I}^{u} \geq \Delta_{1}, P_{I}^{o}=\Delta_{2}$, or (ii) $P_{I I}^{u}=$ $\Delta_{1}, P_{I}^{o}<\Delta_{2}$, then the capacity decisions in both decentralized system and centralized system are identical. Specially, $q_{I}=q_{I I}=q_{c}=F_{3}$.

Proposition 3.2 implies when a smaller service level is given, the suitable penalty scheme is a strong deterrent to two firms. It can improve the final equilibrium in a decentralized system effectively.

Case 2. If $\alpha>\alpha^{*}$ then $q_{c}=F^{-1}(\alpha)$ from Proposition 3.1, let

$$
\begin{aligned}
& F_{1}=F^{-1}(\alpha) ; \quad F_{2}=F^{-1}(\alpha) \\
& \Longrightarrow P_{I I}^{u}=\frac{c_{I I}^{w}-(1-\alpha)\left(p_{I I}-c_{I I}+c_{I I}^{w}\right)}{1-\alpha}=\Delta_{3}, \quad P_{I}^{o}=\frac{(1-\alpha) c_{I I}^{w}}{\alpha}=\Delta_{4} .
\end{aligned}
$$

When $P_{I I}^{u}=\Delta_{3}$, then the constraint in programming (2.7) is $q_{I} \geq F_{1}=F^{-1}(\alpha)=q_{c}$ one item, after the similar analysis that is used in Proposition 2.1(i), we know if $\alpha>\alpha^{*}$, then in a decentralized system the actions of two firms would be coordinated by setting a penalty scheme $P_{I I}^{u}=\Delta_{3}$, and then we will have $q_{I}=q_{I I}=q_{c}=F_{1}=F^{-1}(\alpha)$. Because the given service level $\alpha$ is an only constraint to the decision by firm $I$, and the given service level $\alpha$ is always consistent with the firm II's optimal decision. Hence, the penalty $P_{I}^{o}$ is insignificant. The fact lies behind the penalty is to urge firm II to assign more transport capacity. After further similar discussion, the main result is summarized in Proposition 3.3.

Proposition 3.3. If $\alpha>\alpha^{*}$, then the actions of two firms would be coordinated by designing penalty schemes. Specially (i) $P_{I I}^{u}>\Delta_{3}$ and $P_{I}^{o} \geq \Delta_{4}$ or (ii) $P_{I I}^{u}=\Delta_{3}$.

Proposition 3.3 implies that, when the service level $\alpha$ is relatively higher $\left(\alpha \geq \alpha^{*}\right)$, the two firms would be coordinated only by giving $P_{I I}^{u}=\Delta_{3}$ to firm II. Meanwhile, firm $I$ has to prepare greater amount transport capacity to satisfy the constraint for a higher service level, and the $P_{I}^{o}$ lost its significance. When setting lower penalties to firm $I I\left(P_{I I}^{u}<\Delta_{3}\right)$ the two firms actions would not be coordinated. Meanwhile, firm II's decisions are not improved by setting smaller $P_{I I}^{u}$ which lacks a strong deterrent to undersupply. Therefore, firm I's decision is always larger than firm II's, and it is impossible to coordinate the two firms' action by setting penalties. 


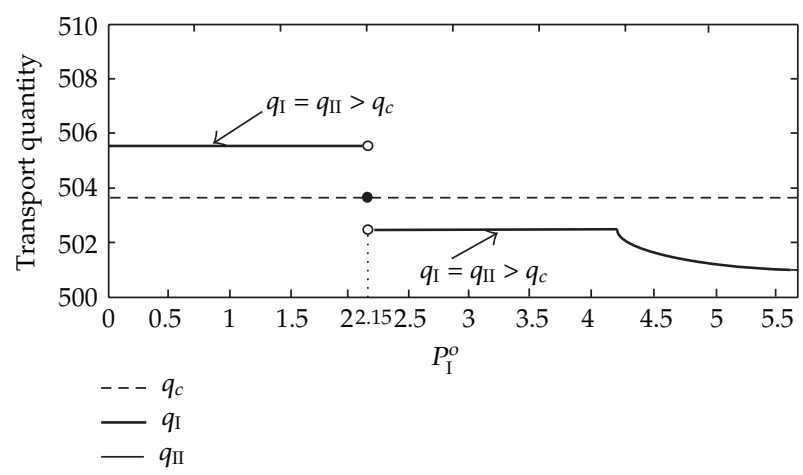

Figure 2: Coordination effects with $P_{I I}^{U}>\Delta_{1}$ and $\alpha<\alpha^{*}$.

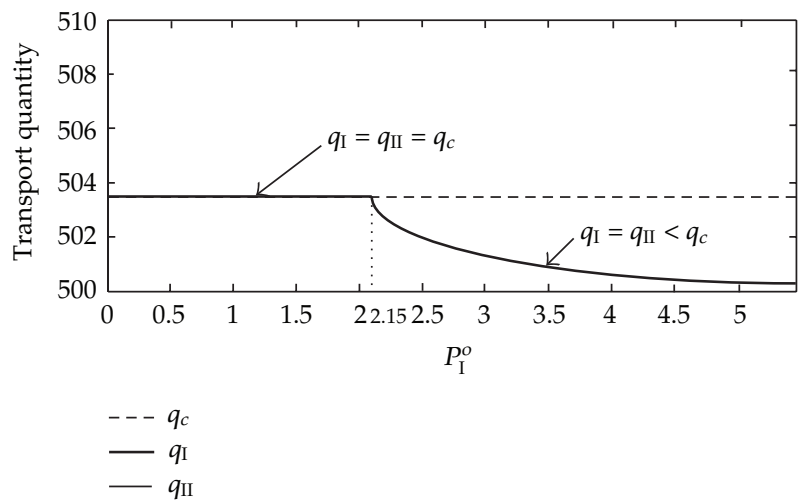

Figure 3: Coordination result under penalties (specially $P_{I}^{U}=\Delta_{1}$ and $\alpha<\alpha^{*}$ ).

\section{Numerical Study}

In this section, we introduce a numerical example to simulate the incentive of coordination mechanisms to separate carriers. As depicted in Figure 1, we adopt the same scenario as in Section 2.1, there are two transport firms with complementary transport model to develop AC intermodal service. A penalty scheme is designed to coordinate the actions between two firms. All parameters which used in example are given, where intermodal freight demand follows normal distribution which the mean value is 500 and the variance is 25 , and $P_{I}=10$, $P_{I I}=8, c_{I}=3, c_{I I}=2, c_{I I}^{w}=4$. Without loss of generality, we assume $\alpha^{*}$ is the critical value of service level and then $\alpha^{*}=0.765$ which is based on the equation $\alpha^{*}=1-c_{I I}^{w} /\left(p_{I}+p_{I I}-\right.$ $\left.c_{I}-c_{I I}+c_{I I}^{w}\right)$. In this section, two cases which are represented $\alpha \geqslant \alpha^{*}$ and $\alpha<\alpha^{*}$ are studied separately to testify the conclusions in the paper.

In the case of $\alpha<\alpha^{*}$, let $\alpha=0.665$, after calculation, we have $\Delta_{1}=7, \Delta_{2}=2.15$, $q_{c}=503.6, \alpha c_{I I}^{w} /(1-\alpha)+c_{I I}-p_{I I}=2, F^{-1}(\alpha)=502.1$. When $P_{I I}^{u} \geq \Delta_{1}$, let $P_{I I}^{u}=8$ and $P_{I I}^{u}=7$ simulate the variation of the game equilibrium, which are depicted in Figures 2 and 3. Let $P_{I I}^{u}=5$, and $P_{I I}^{u}=1$ denote the constraint $\alpha c_{I I}^{w} /(1-\alpha)+c_{I I}-p_{I I}<P_{I I}^{u}<\Delta_{1}$ and $P_{I I}^{u}<\alpha c_{I I}^{w} /(1-\alpha)+c_{I I}-p_{I I}<\Delta_{1}$ to simulate the variation of the equilibrium. The final results are shown in Figures 4 and 5. 


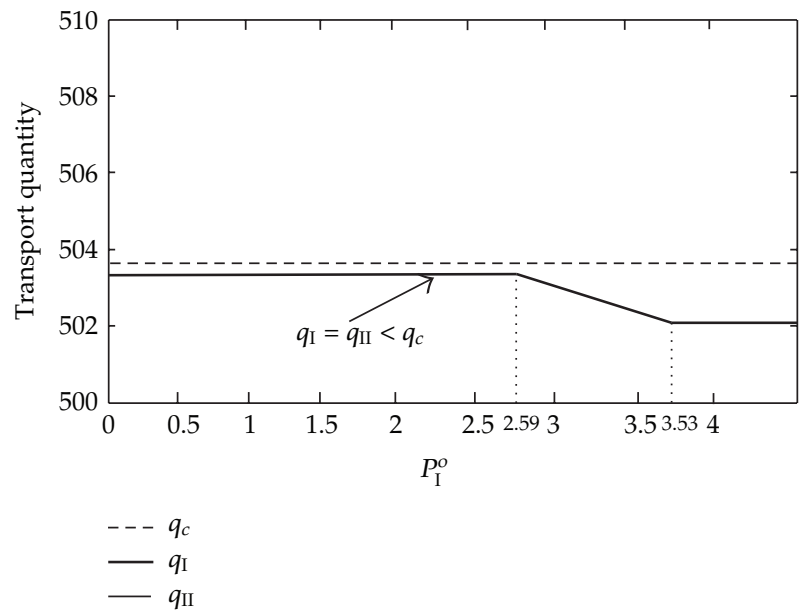

Figure 4: Coordination result under penalties (specially $\alpha c_{I I}^{w} /(1-\alpha)+c_{I I}-p_{I I}<P_{I I}^{u}<\Delta_{1}$ and $\alpha<\alpha^{*}$ ).

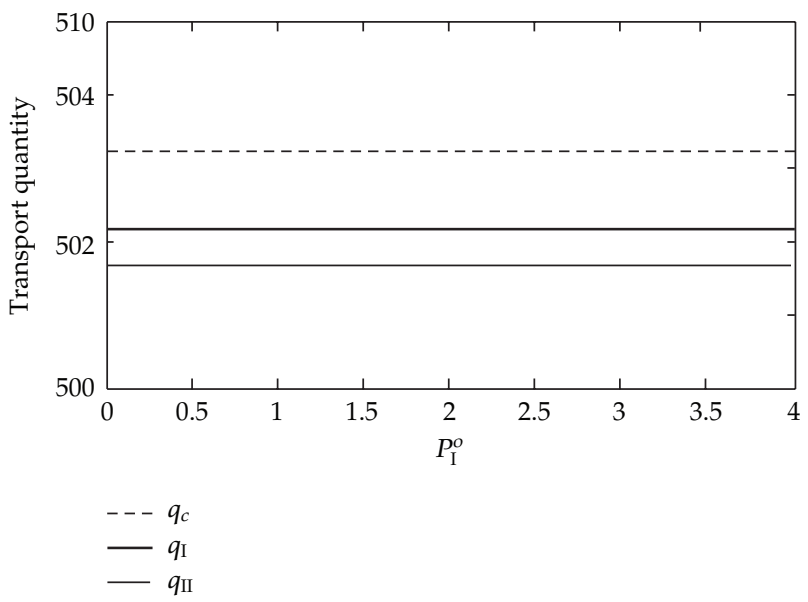

Figure 5: Coordination result under penalties (specially $P_{I I}^{u}<\alpha c_{I I}^{w} /(1-\alpha)+c_{I I}-p_{I I}<\Delta_{1}$ and $\alpha<\alpha^{*}$ ).

From Figure 2, we find the three curves $q_{I}, q_{I I}, q_{c}$ meet at a point if $P_{I}^{o}=2.215$, and the three curves are superposed if $P_{I}^{o} \leq 2.15$ in Figure 3. From Figures 5 and 6, the three curves are never superposed. That implies if $P_{I I}^{u} \geq \Delta_{1}, P_{I}^{o}=\Delta_{2}$, or $P_{I I}^{u}=\Delta_{1}, P_{I}^{o}<\Delta_{2}$ are satisfied, then $q_{I}=q_{I I}=q_{c}$, the actions of two firms are coordinated.

In the case of $\alpha \geqslant \alpha^{*}$, we have $\Delta_{3}=15.8, \Delta_{4}=0.734, q_{c}=505.5$. We also analyze the equilibrium with the variance of penalties. The final results are shown in Figures 6, 7, and 8, where Figure 6 depicts the equilibrium when $P_{I I}^{u}=16\left(P_{I I}^{u}>\Delta_{3}\right)$, Figure 7 depicts the equilibrium when $P_{I I}^{u}=15.8\left(P_{I I}^{u}=\Delta_{3}\right)$, and Figure 8 depicts the equilibrium when $P_{I I}^{u}=14$ $\left(P_{I I}^{u}<\Delta_{3}\right)$, respectively.

From Figure 6, we find the three curves are superposed when $P_{I}^{\mathrm{o}} \geq 0.734$, the three curves are superposed in Figure 7. In Figure 8, nevertheless, there are only two curves $\left(q_{I}, q_{c}\right)$ coincident each other, and the curve $q_{I I}$ lies below other two curves. That means when $\alpha \geqslant \alpha^{*}$, 


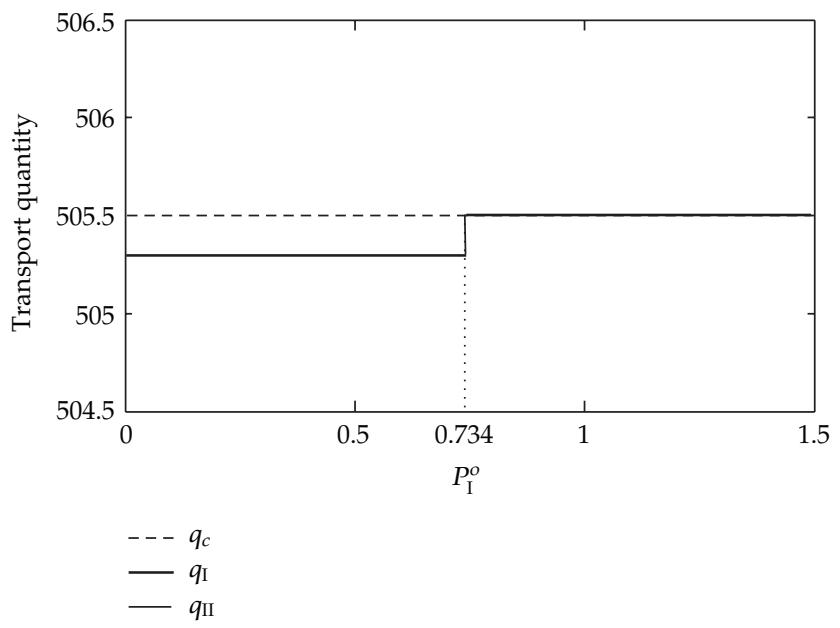

Figure 6: Coordination result under penalties (specially $P_{I I}^{U}>\Delta_{3}$ and $\alpha \geqslant \alpha^{*}$ ).

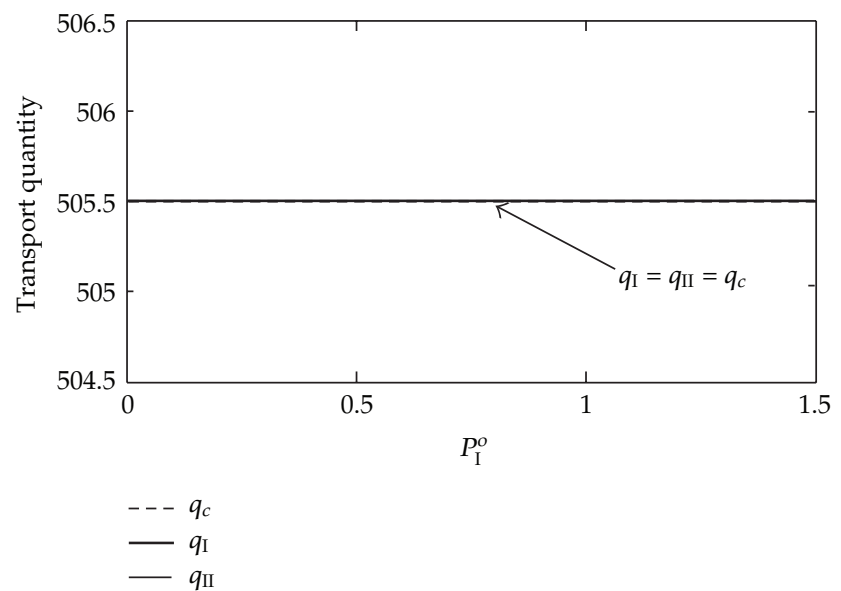

Figure 7: Coordination result under penalties (specially $P_{I I}^{U}=\Delta_{3}$ and $\alpha \geqslant \alpha^{*}$ ).

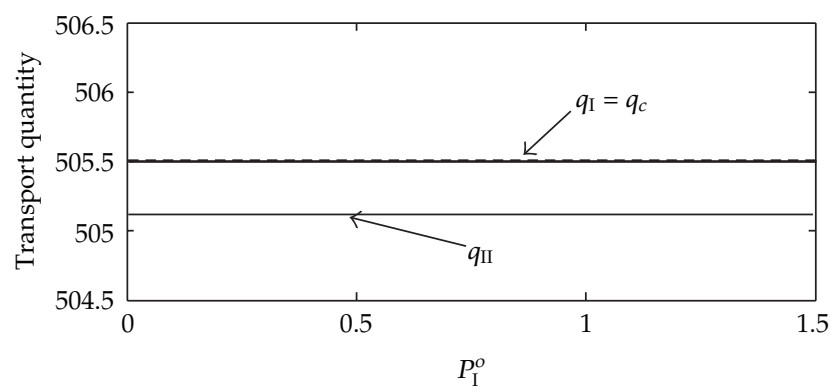

$$
\begin{aligned}
& --q_{c} \\
& -q_{\mathrm{I}} \\
& -q_{\mathrm{II}}
\end{aligned}
$$

Figure 8: Coordination result under penalties (specially $P_{I I}^{U}<\Delta_{3}$ and $\alpha \geqslant \alpha^{*}$ ). 
if $P_{I I}^{u}>\Delta_{3}, P_{I}^{o} \geq \Delta_{4}$, or $P_{I I}^{u}=\Delta_{3}$ are satisfied, then $q_{I}=q_{I I}=q_{c}$, the actions of two firms are coordinated.

The above two case studies show the discordant behaviors would be coordinated by setting suitable coordination mechanisms in a decentralized decision system, and all individual profits would be improved correspondingly. Therefore, all results are consistence with the Propositions in the paper, the validity of Propositions is consequent testified.

\section{Conclusions}

In this paper, a coordinate problem on making freight plan between two separate transport carriers which provide complementary transport service jointly to develop a long haul intermodal service is studied. Two possible decision systems-centralized and decentralized-are taken into consideration, our primary objective is to develop the coordination mechanisms through penalty schemes to coordinate the interactions for two firms in decentralized decision system. In the centralized case, two firms jointly decide on the transport capacity assignment. In the decentralized case, we model a single period problem as a Stackelberg game. Firm $I$, the leader, decides transport capacity to the intermodal service. Firm II, the follower, makes transport capacity assignment based on firm I's action subsequently. Due to the different cost structure and opportunistic behavior by two firms, some discordant decisions would be made subsequently. After detailed models analysis by comparing the final equilibrium made in the two decision systems, some managerial insights are induced. Among other results, we show that one can generate the same result in a decentralized system as what obtained from a centralized system by setting suitable penalties, and that the service level restriction is a significant factor to setting the correct penalty scheme. We also discuss in details the feasible range of penalties to coordinate two firms' decision. All the study in this paper is under the framework of complete information. For the future research, the authors plan to extend the model to the incomplete information, and to make it closer to the real world.

\section{Acknowledgment}

The authors would like to thank the two anonymous referees for helpful comments. This research was supported in part by the Natural Sciences Foundation of China under Grant no. 50968009 and no. 61164003.

\section{References}

[1] C. Macharis and Y. M. Bontekoning, "Opportunities for OR in intermodal freight transport research: a review," European Journal of Operational Research, vol. 153, no. 2, pp. 400-416, 2004.

[2] Y. M. Bontekoning, C. Macharis, and J. J. Trip, "Is a new applied transportation research field emerging?-a review of intermodal rail-truck freight transport literature," Transportation Research $A$, vol. 38, no. 1, pp. 1-34, 2004.

[3] F. Southworth and B. E. Peterson, "Intermodal and international freight network modeling," Transportation Research C, vol. 8, no. 1-6, pp. 147-166, 2000.

[4] B. S. Boardman, E. M. Malstrom, D. P. Butler, and M. H. Cole, "Computer assisted routing of intermodal shipments," Computers and Industrial Engineering, vol. 33, no. 1-2, pp. 311-314, 1997.

[5] A. Muriel and F. N. Munshi, "Capacitated multicommodity network flow problems with piecewise linear concave costs," IIE Transactions, vol. 36, no. 7, pp. 683-696, 2004. 
[6] A. Amiri and H. Pirkul, "New formulation and relaxation to solve a concave-cost network flow problem," Journal of the Operational Research Society, vol. 48, no. 3, pp. 278-287, 1997.

[7] J. Holguín-Veras and E. Thorson, "Modeling commercial vehicle empty trips with a first order trip chain model," Transportation Research B, vol. 37, no. 2, pp. 129-148, 2003.

[8] W. J. Hurley and E. R. Petersen, "Nonlinear tariffs and freight network equilibrium," Transportation Science, vol. 28, no. 3, pp. 236-245, 1994.

[9] F. Xiao and H. Yang, "Three-player game-theoretic model over a freight transportation network," Transportation Research C, vol. 15, no. 4, pp. 209-217, 2007.

[10] A. Zhang, C. Lang, Y. V. Hui, and L. Leung, "Intermodal alliance and rivalry of transport chains: the air cargo market," Transportation Research E, vol. 43, no. 3, pp. 234-246, 2007.

[11] M. Nagarajan and G. Sošić, "Game-theoretic analysis of cooperation among supply chain agents: review and extensions," European Journal of Operational Research, vol. 187, no. 3, pp. 719-745, 2008.

[12] L. A. Guardiola, A. Meca, and J. Timmer, "Cooperation and profit allocation in distribution chains," Decision Support Systems, vol. 44, no. 1, pp. 17-27, 2007.

[13] M. Celikbas, J. George Shanthikumar, and J. M. Swaminathan, “Coordinating production quantities and demand forecasts through penalty schemes," IIE Transactions, vol. 31, no. 9, pp. 851-864, 1999.

[14] J. S. Raju and A. Roy, "Market information and firm performance," Management Science, vol. 46, no. 8, pp. 1075-1084, 2000

[15] G. Cachon, "Supply chain coordination with contracts," in Handbooks in Operations Research and Management Science, pp. 229-246, North-Holland, Amsterdam, The Netherlands, 2003. 


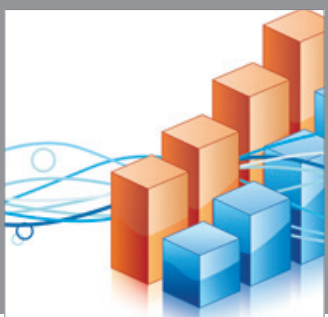

Advances in

Operations Research

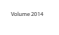

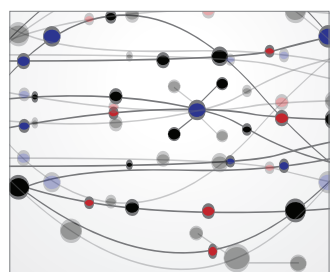

\section{The Scientific} World Journal
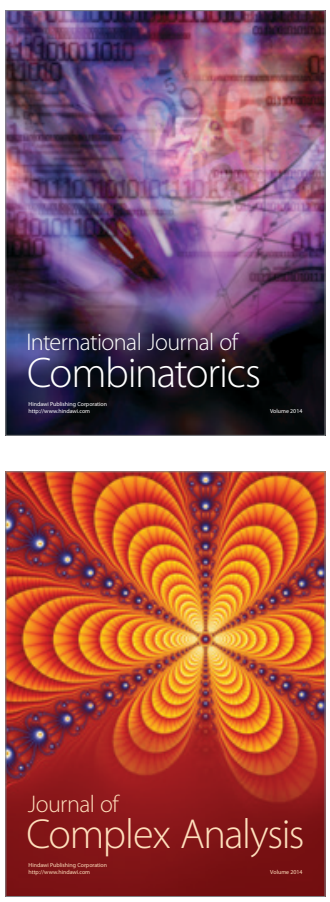

International Journal of

Mathematics and

Mathematical

Sciences
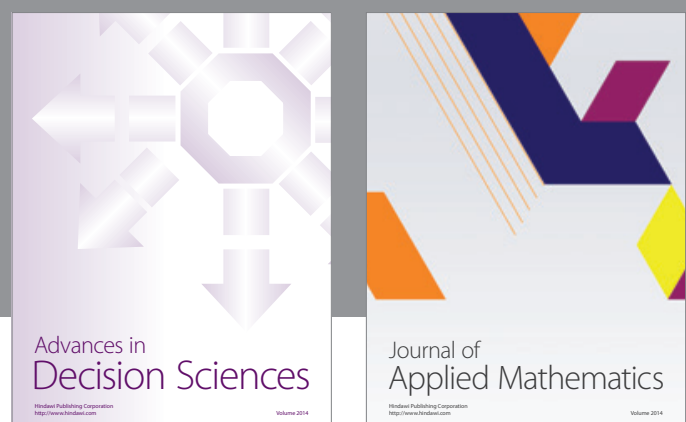

Journal of

Applied Mathematics
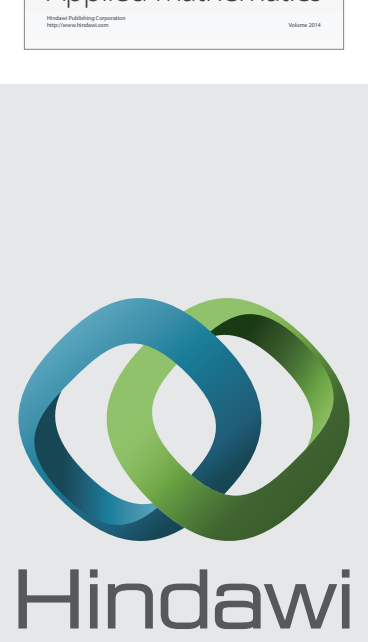

Submit your manuscripts at http://www.hindawi.com
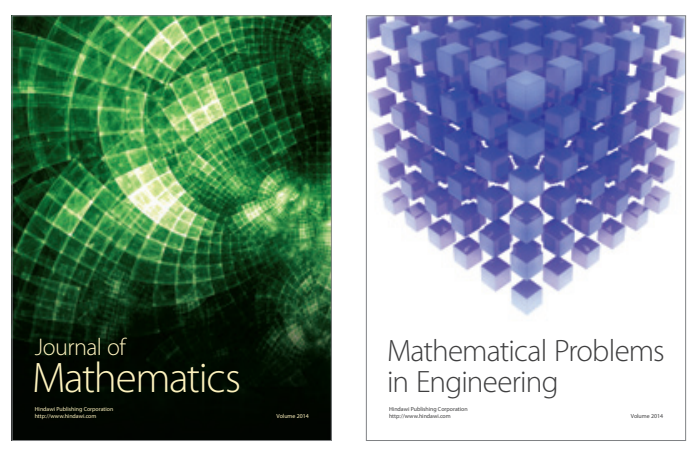

Mathematical Problems in Engineering
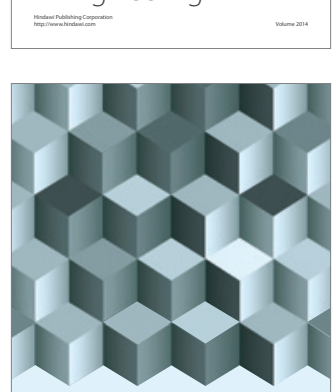

Journal of

Function Spaces
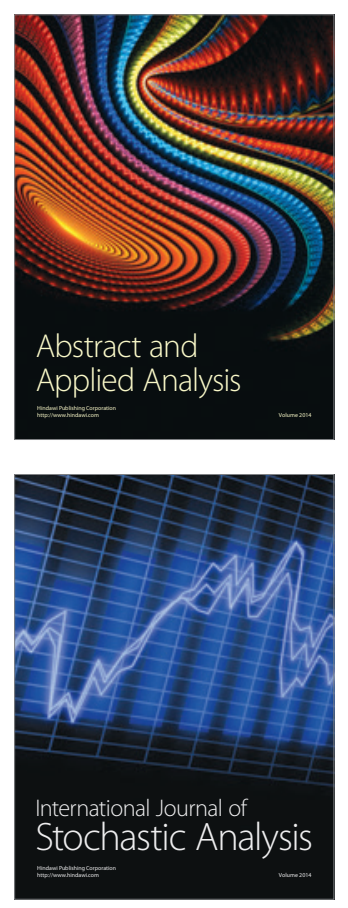

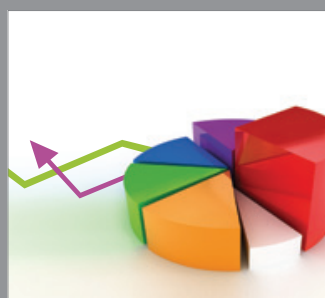

ournal of

Probability and Statistics

Promensencen
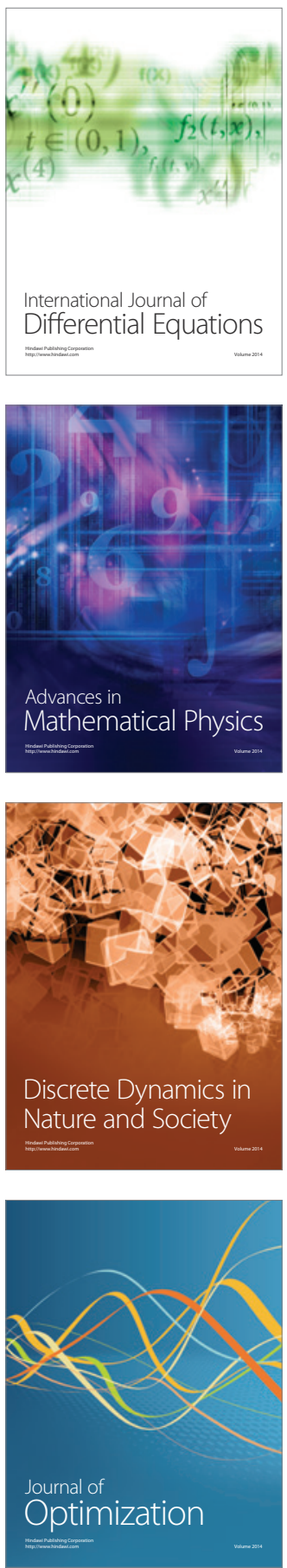